\title{
The Perceived Health Needs of Primiparous Mothers Referring to Primary Health Care Centers: A Qualitative Study
}

This article was published in the following Dove Press journal: International Journal of Women's Health

\author{
Shahin Salarvand (1D' \\ Masoumeh- \\ Sadat Mousavi iD ${ }^{2}$ \\ Darya Esmaeilbeigy ${ }^{3}$ \\ Farahnaz Changaee (iD) 4 \\ Mohammad Almasian ${ }^{5}$ \\ 'Hepatitis Research Center, Faculty of \\ Nursing and Midwifery, Lorestan \\ University of Medical Sciences, \\ Khorramabad, Iran; ${ }^{2}$ Nursing and \\ Midwifery Care Research Center, Isfahan \\ University of Medical Sciences, Isfahan, \\ Iran; ${ }^{3}$ Student Research Committee, \\ Lorestan University of Medical Sciences, \\ Khorramabad, Iran; ${ }^{4}$ Social determinants \\ of Health Research Center, Faculty of \\ Nursing and Midwifery, Lorestan \\ University of Medical Sciences, \\ Khorramabad, Iran; ${ }^{5}$ Department of the \\ English Language, Faculty of Medicine, \\ Lorestan University of Medical Sciences, \\ Khorramabad, Iran
}

Correspondence: Darya Esmaeilbeigy Student Research Committee, Lorestan University of Medical Sciences,

Khorramabad, Iran

Email esmailebigy1399@gmail.com
Background: Since the first step in meeting the health needs of primiparous women involves understanding their conditions, the present study aimed to determine the health needs of primiparous women from their own viewpoints.

Methods: This study had a qualitative approach based on the conventional qualitative content analysis method, in which the purposive sampling method was used. Data were collected by semi-structured interviews. Data saturation was achieved by interviewing 12 participants. To ensure the study was rigorous, the four criteria of credibility, dependability, confirmability, and transferability were taken into account.

Results: The findings of this study consisted of 150 codes, 19 subcategories, and 6 categories, as follows: 1) the intense need for social support, 2) the need for prior preparation for pregnancy, 3) fears and worries, 4) the necessity of the availability of the needed infrastructures and requirements in the health center, 5) falling in love with the baby, and 6) seeking information from appropriate sources.

Conclusion: The present study showed that primiparous women need to receive more social and psychological support from family members and healthcare workers and that it is essential to improve the available infrastructures and services in healthcare centers and to provide the needed counseling to pregnant mothers to enable them to go through the pregnancy period smoothly.

Keywords: health needs, primiparous mothers, primary health care

\section{Background}

Pregnancy and childbirth are among the most important life events for women and are fully personal experiences, ${ }^{1-3}$ the occurrence of which is accompanied by happiness and a sense of personal development as well as immense physical and psychological changes. ${ }^{4,5}$ Although pregnancy is considered an enjoyable physiological phenomenon in a woman's life, physical and mental changes that occur during pregnancy make women psychologically vulnerable. ${ }^{6}$ Since primiparous women undergo these changes and experiences for the first time in their lives, they experience more serious challenges. ${ }^{5,7}$ Therefore, pregnancy, especially among primiparous women, requires physical and mental adjustment. ${ }^{6}$

Every woman has the right to enjoy the highest attainable health status, which includes the right to receive healthcare services with dignity and respect during pregnancy and childbirth as well as the right to be treated nonviolently and without discrimination. ${ }^{8}$ Surveying women's views is a crucial element in improving and 
enhancing maternal (delivery) services. ${ }^{9-12}$ Many studies conducted on the condition of primiparous mothers have shown that primiparous women are very likely to experience postpartum depression, ${ }^{13}$ failure to breastfeed the babies, feelings of being incompetent in carrying out maternal duties, loss of the sense of control, ${ }^{12}$ and inadequate fulfillment of their needs for information and support. ${ }^{12}$ Previous studies have reported that some women experience ambivalent feelings during pregnancy, whereas some other women are afflicted by genuine mental distress. ${ }^{14,15}$

Numerous studies have proposed interventions and solutions to make breastfeeding successful and to help mothers to breastfeed their infants for the recommended duration of time. ${ }^{16}$ Nevertheless, breastfeeding failure and difficulties with breastfeeding are still observed in this group of mothers for various reasons as a failure in performing motherhood roles. ${ }^{17-19}$ Given the fact that human health is the cornerstone of the development of any society, meeting the health needs and requirements of women and mothers who play a significant role in raising the next generation is of great importance. To improve perceived self-competence and perceived stress in breastfeeding and enhance the mental status of pregnant women, the provision of educational interventions alongside conventional care is essential during this period of women's lives. ${ }^{20}$ Qualitative research offers an in-depth understanding of the experiences of pregnant primiparous women, who face new challenges and previously unknown changes in their lives. Since the first step in meeting the health needs of primiparous women is to investigate and comprehend their conditions and needs, primary health care centers (PHCC) were selected as the target study environment because these centers are governmental and most people refer to these centers. The objective was to understand what primiparous pregnant women's experiences were with these centers. The present study aimed to determine the health needs of primiparous women from their own viewpoints.

\section{Methods}

\section{Study Design}

This was a qualitative study with the conventional qualitative content analysis approach. The study was conducted in PHCC affiliated with the Lorestan University of Medical Sciences, Iran.

\section{Participants}

The study population included all primiparous mothers (mean age: 24 years) referring to primary health centers.
The purposive sampling method was used. The inclusion criteria were as follows; a. being a primiparous pregnant woman, $b$. willingness to participate in the study.

\section{Method for Data Collection}

Data collection was carried out via unstructured interviews. Data saturation was achieved after interviewing 12 primiparous mothers. The mean length of each interview was 30 minutes. The time span of conducting interviews was from June to October 2019. The main opening question for the interviews was: "What is your perception of the health care needs of primiparous pregnant women referring to PHCC?" and the subsequent questions were asked according to the study objectives. The interviews were performed in vacant rooms or anywhere that was convenient for the participant. The interviews were conducted by SS and DE wrote them verbatim, then $\mathrm{MM}$ conducted the coding process and obtained the categories, which were revised by two experienced researchers (ie SS and FC). Researchers' observations of the condition of PHCC and participants' non-verbal expressions were recorded as field notes. Data analysis occurred continuously and during the same period as data collection. Content analysis is a research method that is used to uncover individuals' perceptions and views towards the daily phenomena of life, in which the interpretation of the contents of the mental data is based on textual techniques and approaches. ${ }^{21}$ In this method, explicit and implicit notions were determined based on the descriptions offered by the study participants and these notions and concepts were coded, summarized, and categorized and the main themes were extracted. The codes were extracted based on the units of meaning derived from the descriptions offered by the participants and were then categorized based on similarities or differences.

If potential participants were willing to take part in the study, the objectives of the study and the confidentiality of the information were explained to them before the interviews and they were told that the interviews would be recorded.

The analysis of the data obtained from each interview guided and enlightened the next interview and interviews with participants continued until data saturation was achieved.

\section{Data Analysis}

Conventional content analysis was used to analyze the data in the present study. First, the interviews were listened to carefully several times to reach a general understanding of the interviews. Then, the interviews were transcribed 
verbatim. Whole interviews were coded as units of analysis, and words, sentences, and paragraphs from the interview transcriptions were regarded as units of meaning. Next, related units of meaning were grouped based on their main contents and were labeled with a code. After coding, the whole text was reviewed again and the codes were compared and contrasted, grouped under subcategories and categories with increasingly more abstract labels. ${ }^{21}$ Profound and thorough consideration of the categories and their comparison with each other led to the extraction of the implicit content of the interviews, which were expressed as the main themes of the study. Moreover, further findings from the field notes were also incorporated into the study findings.

\section{Trustworthiness of the Data}

To achieve and ensure the methodological rigor of the study, the four criteria of credibility, dependability, confirmability, and transferability were used. To ensure data credibility, methods such as long term engagement of the researcher with the data and the research question and participant review were used. Parts of the interview transcriptions with the initial extracted codes were returned to two participants, and they confirmed whether the codes extracted from the data matched their own views (member check). In other words, reliability and credibility were achieved by obtaining the views and confirmation of the participants regarding the findings.

Confirmability of the findings was assessed and checked by external reviewers who were familiar with qualitative research. That is, parts of the transcribed interviews along with the related codes and categories were examined and verified by two reviewers who were familiar with qualitative research methods. To ensure dependability, the researcher recorded and reported the research procedures thoroughly to allow other researchers to scrutinize the research methods and findings. ${ }^{11}$ To enhance the transferability of the findings, what participants said during the interviews is quoted verbatim. Additionally, the contexts and settings of the study and the demographic information of the participants are presented in detail to allow the readers to determine for themselves whether they can make use of the results of the study. ${ }^{22}$

\section{Ethical Considerations}

Ethical precepts, such as obtaining written informed consent, explaining the objectives of the study to the participants, obtaining the permission of the participants to record the interviews, the confidentiality of the information provided by the participants, and the freedom of the participants to leave the study whenever they wanted were observed. Our study complied with the Declaration of Helsinki. Also the informed consent provided from the participants included consent to quote them in our manuscript. The age range of participants used in this study was 16-32 years old. The Ethics Committee of the Lorestan University of Medical Sciences approved the present study with the ethics code REC.1398.167.

\section{Limitations of Study}

Given that this study was a qualitative research, the participants were selected purposively and according to ethical considerations. There were no constraints in taking part in this study. Therefore, considerable limitations or problems were not observed during the study.

\section{Results}

The findings obtained from the analysis of the interviews included 150 codes, 19 subcategories and 6 categories as summarized below (Table 1):

\section{The Intense Need for Social Support}

This category included 3 subcategories.

The Need to Be the Focus of Attention in the Family The participants reported that they experienced the need to be the center of attention and receive support from their families.

I would have preferred my family and friends to support me more. But they didn't. They objected to my pregnancy, because of the young age at which I had become pregnant. But they expressed their sympathies later on. (P9)

\section{Fear of Being Alone}

The participants also experienced fear of being alone and reported that they were afraid of being left alone due to having no previous experiences with pregnancy.

When my husband is not home because of his job, I feel depressed, I feel lonely. I hate loneliness. (P1)

I felt others should help me. I preferred to have someone accompany me. (P12)

\section{The Need for Support from Health Care Workers}

They felt the need for support from healthcare providers, the need to receive attention and social support from family members and caregivers, and needed to have a calm and stress-free environment at home. 
Table I The Categories and Subcategories of the Data Analysis Process

\begin{tabular}{|c|c|c|}
\hline Subcategory I & Subcategory 2 & Categories \\
\hline The need to be the focus of attention in the family & & Feeling an intense need for social support \\
\hline \multicolumn{3}{|l|}{ Fear of being alone } \\
\hline \multicolumn{3}{|l|}{ The need for support from health care workers } \\
\hline Psychological readiness & & The need for previous preparation and readiness for \\
\hline Financial/Economic readiness & & pregnancy \\
\hline \multicolumn{3}{|l|}{ Physical readiness } \\
\hline Concerns for the health of the fetus & & Fears and concerns \\
\hline \multicolumn{3}{|l|}{ Fear of vaginal delivery } \\
\hline Concerns about how to raise the child & \multirow{2}{*}{$\begin{array}{l}\text { Worrying about and trying to cope with } \\
\text { motherhood roles }\end{array}$} & \\
\hline $\begin{array}{l}\text { Concerns about one's ability to cope with the } \\
\text { challenges of child-rearing }\end{array}$ & & \\
\hline $\begin{array}{l}\text { Access to psychoeducation counseling/psychological } \\
\text { consultation }\end{array}$ & & $\begin{array}{l}\text { The necessity of having adequate infrastructures and human } \\
\text { resources in health centers }\end{array}$ \\
\hline \multicolumn{3}{|l|}{ Access to nutritional consultation } \\
\hline \multicolumn{3}{|l|}{$\begin{array}{l}\text { The need to have a close and informal relationship } \\
\text { with health care workers }\end{array}$} \\
\hline \multicolumn{3}{|l|}{ The need for appropriate education and information } \\
\hline Becoming inattentive to marginal issues & \multirow{3}{*}{$\begin{array}{l}\text { The beautiful emotions of becoming a mother } \\
\text { and loving the baby }\end{array}$} & \multirow[t]{3}{*}{ Falling in love } \\
\hline Embracing the baby & & \\
\hline Feeling love for the fetus & & \\
\hline Being interested in participating in educational classes & & Seeking appropriate information \\
\hline Seeking the needed information on the Internet & & \\
\hline
\end{tabular}

I expect to have a peaceful environment and have a good relationship with my husband. (P10)

During pregnancy, my significant others and health care workers should pay more attention to me and be kinder to me. (P5)

\section{The Necessity of Prior Readiness for Pregnancy}

The participants emphasized the need for psychological readiness, financial/economic readiness, and physical readiness before trying to get pregnant.

I recommend that would-be mothers plan well ahead for their pregnancies. (P2)

To become pregnant, they should first be ready for pregnancy, both mental and financial readiness. You must be ready to have a new person in your life. Because you will have many responsibilities towards him or her. It requires mental and psychological readiness and peacefulness. It requires financial readiness so that you can raise your kid with confidence and without stress. (P11)

\section{Fears and Worries}

This category had the three subcategories of concerns for the health of the fetus, attempts to adjust to motherhood roles and fear of vaginal delivery.

All participants stated their concerns for the health of fetus:

I am concerned about the health condition of my fetus.

I imagine its position and I feel its movement and it makes me happy. (P10)

Some participants who had become pregnant at a young age recounted the fears they experienced and how what others said affected their psychological conditions. 
What others say influences me, because I do not have any experiences, and this makes me fearful and worried. (P6)

Some participants expressed willingness to undergo a caesarian section because they were afraid of natural childbirth.

I was very worried about giving birth the natural way. I was afraid of the pain and other issues. I became inclined to give birth by caesarian section. (P3)

\section{The Need for the Necessary Infrastructures and Requirements in Health Centers}

This category emerged from the subcategories of the need for the availability of psychological counseling, access to a nutritional consultant, the need for a close and informal relationship with the healthcare workers, the need to receive appropriate education and information, the need for the development of a suitable physical space, and the need for a privacy-oriented environment.

In the present study, the participants reported that the desks of the caregivers were quite close to each other and no caregiver had any private space to themselves, which led to dissatisfaction with the services among the pregnant mothers because of concerns for privacy.

The physical space of the clinic is not satisfactory. The healthcare staff should have separate rooms for their work. Pregnant mothers may not like to be overheard by others. They may not want others to know about their personal and private problems. (P8)

The psychological changes during this period, such as becoming more sensitive and touchy, and experiencing anxiety, depression, and loneliness necessitates receiving psychological counseling to allow one to unbosom one's troubles. (P2)

\section{Falling in Love with the Baby}

This category includes the subcategories of becoming inattentive to marginal and trivial issues, embracing the baby, the development of love and attachment to the baby.

Some participants described their experience of feeling love for their babies and developing attachments to them, which made them disregard lesser issues.

It's a beautiful emotion. You feel you are falling in love. Attachment to the fetus that is growing in the womb is really enjoyable. (P10)
The attention I pay to the fetus and the attachment that I have to the child makes me neglect marginal issues. (P9)

\section{Seeking Information from Appropriate Sources}

This category includes two subcategories as follows: showing interest in attending educational classes, searching on the Internet.

The participants tried to meet their own needs for education and information about pregnancy via educational classes and searching on the Internet.

I search on the Internet to find the answers to my questions, for instance, about nutrition during pregnancy and other questions. (P4)

I was interested in participating in the educational classes held by the health center about self-care in pregnant mothers and readiness for breastfeeding and I attended these classes. (P7)

\section{Discussion}

This study was conducted to determine and explore the health needs of primiparous women from their viewpoints.

\section{Category I: The Intense Need for Social Support}

This category consisted of the subcategories of the need for being the center of attention, the need for support from family members, fear of being alone, and the need for support from healthcare providers.

In the present study, the participants expressed their perceived needs for being the focus of attention and receiving support from their families, fear of solitude, and the need to receive support from the healthcare staff. Other studies have also confirmed the fact that a lack of familial support is a determining factor in fear of giving birth. ${ }^{9}$ The fear of childbirth and parenting children can be ameliorated by access to proper support. Access to close and trustworthy friends and family members can generate feelings of security and well-being and can reduce the anxiety experienced during pregnancy. ${ }^{12}$

The participants in this study emphasized the need for a peaceful and stress-free environment and satisfactory matrimonial relationships with their husbands. Other studies have also maintained that one of the most important factors in the adjustment of pregnant women during this period is the emotional support received from the husband 
in a secure matrimonial setting. Lack of attachment to the familial setting and, in general, any kind of disruption in matrimonial relationships can heighten anxiety levels and lead to an aversion to pregnancy and endanger the health of the pregnant woman. ${ }^{7}$ Physical, intrapersonal, and familial adjustment and adaptation are crucial to achieving successful adjustment with pregnancy and childbirth.

Furthermore, the participants pointed out the need for support from healthcare providers and good relationships with the healthcare personnel. Fenwick et al reported that some women consider the information and support received from medical services, hospital staff, friends, and family members as effective in reducing the fear of childbirth and parenting. ${ }^{12}$ They demonstrated that care models are required to allow healthcare workers and women to communicate and relate appropriately so that trustworthy relationships can be established. ${ }^{12}$ Listening carefully to the worries of pregnant women and responding in a manner that validates their feelings and expectations can pave the way for sensitive discussions on delivery and childbirth to occur. ${ }^{12}$ In a study by Ternström, women mentioned that establishing trust with healthcare workers was the strategy that helped them cope with their worries and fears. ${ }^{9}$ Support and Education help mothers gain a better understanding of themselves and recognize their weaknesses and strengths, such that, by acquiring self-knowledge, they can take steps to amend their weaknesses and augment their strengths. ${ }^{20}$

\section{Category 2: Prior Preparation for Pregnancy}

This category subsumes the subcategories of psychological readiness, financial/economic readiness, and physical readiness.

In the present study, the participating mothers emphasized the prior psychological, financial/economic, and physical preparation and readiness for pregnancy. Findings from other studies support this point. Hickey et al showed that risk factors such as being very young at pregnancy, being alone, having unfavorable socioeconomic conditions, household poverty, a stressful lifestyle, and lower educational attainment levels were associated with a decline in self-efficacy in raising infants and more manifestations of the symptoms of depression. The concomitant presence of several risk factors reduces the emotional support the infant receives and lowers cognitive stimulation. Primiparous women face even bigger challenges. The inability of primiparous women to offer emotional support to infants could be due to lack of experience, which explains why primiparous women need even more preparations and readiness by receiving various types of support and by learning child-raising strategies. ${ }^{23}$

\section{Category 3: Fears and Worries}

This category emerged from the subcategories of concerns for the health of the fetus, worries, and attempts to adjust to the maternal role and fear of vaginal delivery. Arefi et al also reported fear of childbirth and its pain to be among the main factors leading to anxiety during pregnancy. Natural childbirth is a more painful and dangerous process from the viewpoint of pregnant women. Fear of harm to the mother as well as the fetus and the effect it will have on the health of the baby in the future are also important factors in causing anxiety in pregnant women. ${ }^{24}$ Other studies confirm this issue as well, such that the fear of childbirth is a tangible reality for Australian women. ${ }^{12}$ Primiparous mothers attribute this fear to a lack of experience and insecurity about doing things they have never done before. ${ }^{9}$ In general, several studies have shown that fear of vaginal delivery during pregnancy is quite common and is the most common underlying reason for requesting cesarean section (CS) even when it is not medically indicated. ${ }^{8,25,26}$

A CS-related phenomenon that has attracted worldwide attention is the fear of childbirth and the factors surrounding the manifestation of this fear. ${ }^{12}$ Fenwick et al showed that fear of the unknown and vague expectations were the main sources of anxiety in women who had no history of childbirth. $^{12}$

\section{Category 4: The Need for Adequate Infrastructures and Human Resources in the Health Care Center}

This category includes the following subcategories: The availability of psychological counseling, access to a nutritional consultant, the need for close and informal communication with the healthcare staff, the need for proper pregnancy education and information, the need to develop the physical space appropriately, such that concerns for privacy are taken into account.

In the present study, the need for access to psychological counseling in clinics was mentioned by primiparous mothers. The findings of the study by Fenwick et al showed that psychoeducation counseling interventions designed and developed in a psychological framework 
based on boosting and supporting resilience, selfconfidence and sense of competence are likely beneficial to women who do not have a good understanding of their self-efficacy and have low self-esteem. ${ }^{12}$

In the present study, the participants pointed out the need for access to nutritional consultation in the clinics. The findings of a study by Sword et al confirm that recommendations such as following a proper diet, controlled and correct weight gain, and receiving explanation of risk factors help women choose healthier lifestyles. ${ }^{27}$

In the present study, the participants expressed the need to receive appropriate education and information. The findings of a study by Sword et al also established that women paid attention to and followed the recommendations of healthcare providers about health promotion and disease prevention. ${ }^{27}$ Learning how to cope with stressful situations during pregnancy can improve women's mental health during this period. $^{28}$

In the present study, participants noted the need for close and informal communication with health care workers. The findings of the study by Sword et al demonstrate that healthcare providers play a key role in the quality of prenatal care from the viewpoint of women. Pregnant mothers expect healthcare providers to treat them respectfully, to value their feelings, and to take time to address their problems. Building a relationship based on trust is an important skill for healthcare providers. Establishing appropriate relationships leads to the active involvement of the clients in the care process, reduced anxiety levels, and better compliance with the recommendations. ${ }^{27}$

In the present study, the participants said that the physical space in health clinics should be developed appropriately. Findings from the study by Sword et al also confirm that pregnant mothers cited cleanliness, a beautiful environment, and good physical space as factors affecting the quality of care. ${ }^{27}$

In the present study, one of the stated needs of primiparous mothers was the need for privacy in terms of the physical space of the clinic. This is in line with the findings of the study by Sword et al in which, according to women, cleanliness, a beautiful environment, and privacy are necessary features for health centers. Privacy refers to the existence of a space where one can easily disclose one's problems with healthcare providers. In this study, conversations with healthcare providers being overheard by others were one of the most important violations of privacy. $^{27}$

\section{Category 5: Falling in Love}

This category was divided into the subcategories of inattentiveness to marginal issues, embracing the child, attachment to and love for the fetus.

The present study showed that primiparous women experience attachment to the fetus and become oblivious to marginal issues during their pregnancies. Attachment refers to the initial emotional relationship between mother and fetus. ${ }^{29}$ Other studies indicate that when pregnancy is confirmed, women experience a combination of different emotions. Women believe that a new life is taking shape in their bodies and they feel intensely and emotionally attached to this new life (fetus). During pregnancy, women imagine the development of the fetus and its physical changes, so they are eager to give birth and see their baby. ${ }^{30}$ In a study by Tafazoli et al, it was found out that attachment is an important part of the pregnancy process and is considered one of the predictors of the establishment of emotional relationship and interaction with the baby. ${ }^{31}$

\section{Category 6: Seeking Appropriate Information}

This category included the subcategories of interest in participating in educational classes and searching on the Internet. Pregnancy causes women to prioritize healthrelated behaviors above all else, which ultimately promotes their health and that of their fetus. ${ }^{30}$ Salary et al showed that gaining knowledge and awareness creates a sense of control and helps individuals to use effective and consistent coping strategies. ${ }^{32}$

Aston et al showed that primiparous women use a variety of sources to get information (about baby care and maternal health) such as family members, health professionals (such as doctors, nurses, midwives), friends, and online resources. Mothers evaluate this information, which becomes the basis for their decisions. People continue to seek information from various sources as long as they feel that the obtained information is useful and can be used as a tool to evaluate their performance. Seeking information is especially important for primiparous mothers because they need reliable information to perform their maternal responsibilities, especially since they have no prior experience with childbirth and child-rearing. In some cases, mothers stop asking for information, especially from the medical staff, because they feel that they might be questioned and judged on their ability to take on the 
responsibilities of motherhood. The mother's ability to receive and organize information gives her a sense of selfconfidence and self-efficacy in taking care of herself and her families. ${ }^{33}$

Another study by Price et al suggested that mothers' primary goal in seeking information was to make sure that the baby is developing healthily. In addition to emphasizing the importance of information received from the medical staff, mothers consider other mothers as important sources of information. Communicating with other mothers means sharing of information among people who have had common experiences. This method of obtaining information can also be considered as some sort of social and spiritual support because sharing negative experiences helps the mother understand the commonality of these problems for other mothers and helps her conclude that her efforts to improve maternal efficacy have been fruitful. ${ }^{34}$ Access to authoritative sources of information allows women to feel more confident, and to form mental expectations and ideals about their pregnancy and childbirth. $^{12}$

\section{Conclusion}

The present study demonstrated that primiparous women need more social and psychological support from family members and health care workers due to lack of experience and revealed the need for adequate infrastructures and human resources at health care centers and the need for access to counseling during pregnancy. Although in the present study, mothers sought to obtain the health information they needed, they expected to obtain more information through the healthcare system. The feeling of anxiety and uncertainty brought about by the lack of proper fulfillment of the need for information caused them to seek this information themselves. However, other studies have shown that the use of multiple sources leads to conflict and a sense of despair and the contradictions between the views of different sources put mothers in a state of indecision. ${ }^{33}$ It is strongly felt that healthcare workers should manage and meet the mothers' needs for accurate information.

\section{Acknowledgments}

This study is the result of a research project approved by the Student Research Committee of the Lorestan University of Medical Sciences with the project code 1228. The authors would like to thank the study participants, as well as the staff of the Student Research
Committee and the Vice Chancellorship for Research of the University of Medical Sciences.

\section{Funding}

The vice Chancellorship for Research of the Lorestan University of Medical Sciences, Iran.

\section{Disclosure}

The authors report no conflicts of interest for this work.

\section{References}

1. Robinson AM, Benzies KM, Cairns SL, Fung T, Tough SC. Who is distressed? A comparison of psychosocial stress in pregnancy across seven ethnicities. BMC Pregnancy Childbirth. 2016b;16(1):215. doi:10.1186/s12884-016-1015-8

2. Jourabchi Z, Roshan Z, Alipour-Heidari M, Ranjkesh F. Effect of group counseling on the type of delivery in nulliparous women: a randomized controlled trial. Sci J Hamadan Nurs Midwifery Faculty. 2018;26(2):120-128. doi:10.30699/sjhnmf.26.2.120

3. Wilde-Larsson B, Larsson G, Kvist LJ, Sandin-Bojö AK. Womens' opinions on intrapartal care: development of a theory-based questionnaire. J Clin Nurs. 2010;19(11-12):1748-1760. doi:10.1111/ j.1365-2702.2009.03055.x

4. Davoudi Z, Khodabakhshi-Kolaee A, Falsafinejad M. The effectiveness of training of self-help program toward the parenthood on worry in pregnancy period among the nulliparous women. $J$ Health Lit. 2018;3(1):61-71. doi:10.22038/jhl.2018.10932

5. Adel A, Basaknejad S, Hamid N, Davoudi I. The effectiveness of mental health training of mother and child on pregnancy anxiety and mental health of primigravida mothers. J Nurs Midwifery Urmia Univ Med Sci. 2018;16(8):583-592. [In Persian].

6. Monfared Kashki M, Maleki A, Amini K, Faghihzadeh S. Effect of spirituality-based consultation on coping patterns with pregnancy challenges in primigravida women. $J$ Mazandaran Univ Med Sci. 2019;29(176):81-91. [In Persian].

7. Aghayosefi AR, Moradi K, Safari NA, Ghazi S, Amiri F. The study of the relationship between marital satisfaction with physical problems during pregnancy and the related factors in pregnant women of khorramabad city. Yafteh. 2011;13(1):125-134. [In Persian].

8. Högberg U, Lynöe N, Wulff M. Cesarean by choice? Empirical study of public attitudes. Acta Obstet Gynecol Scand. 2008;87 (12):1301-1308. doi:10.1080/00016340802482978

9. Ternström E, Hildingsson I, Haines H, Rubertsson C. Pregnant women's thoughts when assessing fear of birth on the fear of birth scale. Women Birth. 2016;29(3):e44-e9. doi:10.1016/j.wombi.2015.11.009

10. Elo S, Kääriäinen $M$, Kanste $O$, Pölkki T, Utriainen K, Kyngäs $H$. Qualitative content analysis: A focus on trustworthiness. SAGE Open. 2014;4(1):215824401452263. doi:10.1177/2158244014522633

11. Thomas E, Magilvy JK. Qualitative rigor or research validity in qualitative research. J Spec Pediatr Nurs. 2011;16(2):151-155. doi:10.1111/j.1744-6155.2011.00283.x

12. Fenwick J, Toohill J, Creedy DK, Smith J, Gamble J. Sources, responses and moderators of childbirth fear in Australian women: a qualitative investigation. Midwifery. 2015;31(1):239-246. doi:10.1016/j.midw.2014.09.003

13. Holopainen A, Hakulinen T. New parents' experiences of postpartum depression: a systematic review of qualitative evidence. JBI Database System Rev Implement Rep. 2019;17(9):1731-1769. doi:10.11124/JBISRIR-2017-003909

14. Hofberg K, Brockington I. An unreasoning dread of childbirth: a series of 26 cases. Br J Psychiatry. 2000;176:83-85. doi:10.1192/ bjp.176.1.83 
15. Fenwick J, Gamble J, Nathan E, Bayes S, Hauck Y. Pre-and postpartum levels of childbirth fear and the relationship to birth outcomes in a cohort of Australian women. J Clin Nurs. 2009;18(5):667-677. doi:10.1111/j.1365-2702.2008.02568.x

16. Dennis C-L, Hodnett E, Gallop R, Chalmers B. The effect of peer support on breast-feeding duration among primiparous women: a randomized controlled trial. CMAJ. 2002;166(1):21-28.

17. Kheirabadi G-R, Maracy M-R, Barekatain M, Casey PR. Risk factors of postpartum depression in rural areas of Isfahan Province, Iran. Arch Iran Med. 2009;12(5):461-467. PMID: 19722767.

18. Savabi Esfahani M, Fathizadeh N. Continuous exclusive breastfeeding and some related factors in the selected hospitals of Isfahan. Iran J Nurs Midwifery Res. 2011;16(3):207. PMID: 22224108.

19. Charkazi A, Miraeiz SZ, Razzaghnejad A, Shahnazi H, Hasanzadeh A, Badleh MT. Breastfeeding status during the first two years of infants' life and its risk factors based on BASNEF model structures in Isfahan. $J$ Educ Health Promot. 2013;2:9. doi:10.4103/2277-9531.107938

20. Mohammad Pour A, Najafi S, Tavakoli Zadeh J, Mohammad Zadeh F. The effect of intervention based on "Roy" adaptation model on personal self-concept in primigravida women. J Sabzevar Univ Med Sci. 2016;22(6):999-1007. [InPersian].

21. Hsieh H-F, Shannon SE. Three approaches to qualitative content analysis. Qual Health Res. 2005;15(9):1277-1288. doi:10.1177/ 1049732305276687

22. Speziale HS, Streubert HJ, Carpenter DR. Qualitative Research in Nursing: Advancing the Humanistic Imperative. Lippincott Williams \& Wilkins; 2011.

23. Hickey G, McGilloway S, Leckey Y, et al. Mothers' well-being, parenting attitudes, and home environment: cumulative risk and parity in early motherhood. Child Care Health Dev. 2019;45 (4):523-530. doi:10.1111/cch.12677

24. Arfaie K, Nahidi F, Simbar M, Bakhtiari M. The role of fear of childbirth in pregnancy related anxiety in Iranian women: a qualitative research. Electronic Physician. 2017;9(2):3733. doi:10.19082/3733
25. Saisto T, Halmesmäki E. Fear of childbirth: a neglected dilemma. Acta Obstet Gynecol Scand. 2003;82:201-208. doi:10.1034/j.16000412.2003.00114.x

26. Molgora S, Fenaroli V, Prino LE, et al. Fear of childbirth in primiparous Italian pregnant women: the role of anxiety, depression, and couple adjustment. Women Birth. 2018;31(2):117-123. doi:10.1016/j. wombi.2017.06.022

27. Sword W, Heaman MI, Brooks S, et al. Women's and care providers' perspectives of quality prenatal care: a qualitative descriptive study. BMC Pregnancy Childbirth. 2012;12(1):29. doi:10.1186/1471-239312-29

28. Bastani F, Haidarnia A, Vafaie M, Kazem-nejad A, Kashanian M. The effect of relaxation training based on self-efficacy theory on mental health of pregnant women. Iran J Psychiatry Clin Psychol. 2006;12(2):109-116. [In Persian].

29. Saastad E, Ahlborg T, Frøen JF. Low maternal awareness of fetal movement is associated with small for gestational age infants. J Midwifery Womens Health. 2008;53(4):345-352. doi:10.1016/j. jmwh.2008.03.001

30. Leva-Giroux RA Prenatal Maternal Attachment: the Lived Experience [Thesis for DNSc degree]. University of San Diego; 2003. eLIBRARY ID: 5384769

31. Taffazoli M, Aminyazdi SA, Shakeri MT. The relationship between maternal-fetal attachment and mother-infant attachment behaviors in primiparous women referring to Mashhad health care centers. J Midwifery Reprod Health. 2015;3(2):318-327.

32. Salari M, Kashaninia Z, Davachi A, Zoladl M, Babaie G. Effect of education on coping strategies of mothers who have educable mentally retarded children. Armaghane-Danesh. 2001;6(23):1-9. [In Persian].

33. Aston M, Price S, Monaghan J, Sim M, Hunter A, Little V. Navigating and negotiating information and support: experiences of first-time mothers. J Clin Nurs. 2018;27(3-4):640-649. doi:10.1111/ jocn. 13970

34. Price SL, Aston M, Monaghan J, et al. Maternal knowing and social networks: understanding first-time mothers' search for information and support through online and offline social networks. Qual Health Res. 2018;28(10):1552-1563. doi:10.1177/10497323177483

\section{Publish your work in this journal}

The International Journal of Women's Health is an international, peerreviewed open-access journal publishing original research, reports, editorials, reviews and commentaries on all aspects of women's healthcare including gynecology, obstetrics, and breast cancer. The manuscript management system is completely online and includes a very quick and fair peer-review system, which is all easy to use. Visit http://www.dovepress.com/testimonials.php to read real quotes from published authors. 